A Bibliography of Metallic Corrosion : comprising References to Papers on Ferrous and Non-Ferrous Corrosion (including Methods of Protection) published up to end of 192\%. Greatly enlarged from a Bibliography prepared for the British NonFerrous Metals Research Association and privately issued to its Members. By Dr. W. H. J. Vernon. Pp. xi +341 . (London: Edward Arnold and Co., 1928.) 21s. net.

THE literature of corrosion is extensive and at the same time widely scattered, so that a student of the subject feels the need of a bibliography more than in most branches of applied physical chemistry. Several attempts at such a compilation have been made, but certainly with less success than in the present work, which is likely to prove of great value to chemists and to metallurgists. At first sight it may be thought that the classification which Dr. Vernon has adopted is not the simplest, since there is no alphabetical index of authors, and the arrangement is one of many sections, each of which covers a definite part of the subject. After using the book for a short time, however, it is found that there is no difficulty in tracing any required paper the author of which is known, whilst a thorough system of cross-references ensures that the papers likely to have a bearing on any particular question can be traced with little effort. The bibliography has responded well to the test of looking for known memoirs.

There is no attempt to give the exact title of each paper, a short indication of the subject being given in English, but the original reference is accompanied by references to abstracts in the most accessible English and American journals. When necessary, a brief abstract is added, and this part of the work has been done judiciously, so that the reader is guided to essential papers without having to consult a large mass of material of no importance to his immediate subject. Dr. Vernon is to be congratulated on having performed a useful task with success.

\section{H. D.}

\section{Miscellany.}

History and Historical Research. By C. G. Crump. Pp. $\mathrm{x}+178$. (London: George Routledge and Sons, Ltd., 1928.) 5s. net.

THIS is a delightful and stimulating little book. Mr. Crump held an important position in the Public Record Office for many years, but he writes in a spirit which would be equally becoming in a scientific laboratory. In fact, his essay is one of the best proofs we have seen of the essential similarity between all forms of work which aim at increasing knowledge of a living kind. Almost everything he says might be said with equal truth about scientific research.

Mr. Crump starts with the primary and fundamental necessity of an inquiring mind. Every researcher must be possessed with the desire to know. In this he only shares the characteristic which Aristotle assigned to the human species as a whole; when he adds to this the mark of wanting to know something new, or more about something than anyone else knows, he takes rank among original researchers-those who add to the sum of human knowledge. But in order to do this he must at starting be provided with a considerable equipment of general knowledge, and no part of Mr. Crump's book is better than where he dwells on the supreme importance of a well-trained mind in judging of the likely field for research and of the value of evidence, and in presenting it in a lucid and well-ordered form.

Two other admirable features stand out in this manual for the young researcher. One is the insistence on self-reliance. The choice of subject must be individual, and the professor, or older and more experienced colleague, should assist as friend and equal, not as dictator or superior. All the details of his method-the note-taking, and arrangement, the planning and writing of the book-will be subordinate to the main idea, and grow under his hand as he works. In short, the researcher, be he historian or man of science, is master of his own fate, and no one can make or mar it but himself.

Another attractive feature of the book is the style in which it is written, and the constant quiet humour which irradiates the whole. There is no better example of this than the analogy of the choice of a subject with the chase of a lion. The researcher has first to delimit the area in which he may find his quarry. This in itself demands wide knowledge and careful preliminary survey: by these the true haunts of the subject are ascertained. The searcher then advances, slowly and steadily testing and securing all the means of approach; and when at last the noble object of his quest stands before him, he is just as likely to be devoured by the quarry as to make it his own. The former indeed may seem as fine and fitting a reward as the latter.

$$
\text { F. S. M. }
$$

The Evolution and Classification of Soils. By Dr.

E. Ramann. Translated by Dr. C. L. Whittles. Pp. xii +127 . (Cambridge: W. Heffer and Sons, Ltd. ; London: Simpkin Marshall, Ltd., 1928.) $7 s .6 d$. net.

StaRting with a definition of soil, the author brings together many of the ideas and systems which have been developed throughout the world for its scientific classification. After discussing briefly the advantages and disadvantages of various methods of classifying soils, a system is adopted which, although almost too wide for general use, is not subject to the serious limitations of most of the older classifications. A soil is classified in accordance with its ' zone ' (latitude and longitude) and its 'region' (depending on height, position, humid or arid climate, etc.).

Most soil workers nowadays have a little knowledge of the Russian pedological classifications and nomenclature, and this has proved in many cases a dangerous thing. Those who want to know the exact meaning of podsol, tschernosem, and similar terms frequently used and mis-used in recent works 